\title{
THE ARTS IN HEALTH PROFESSIONS EDUCATION
}

\section{From Atoms, Molecules, and Numbers to Literature, Art, and Performance}

\author{
J. Russell Teagarden, DMH, MA, BSPharm \\ Submitted April 22, 2019; accepted May 26, 2019; published April 2020.
}

\begin{abstract}
I argue that the humanities have an important role in pharmacy education. I came to this view after believing the humanities to be useless and superfluous when I was in pharmacy school and during the earlier phases of my career. I eventually learned that the humanities can teach us a lot that the biomedical sciences can not, and that the humanities can expand on a lot of what the biomedical sciences do teach us. My argument derives from a model that makes a distinction between the disease and illness components of health problems, which makes it possible to see how biomedical sciences focus on disease and how the humanities focus on illness. Because medical schools have adopted the humanities into their education and training programs, I also argue that pharmacists will need a similar grounding if they are to collaborate with physicians on the same terms.
\end{abstract}

Keywords: humanities, pharmacy education

At every registration period during pharmacy school in the mid-1970s, I was forced to consider British literature or American poetry among the electives listed. I was offended. Science was all I needed, and the arts that constitute the humanities had nothing to offer me in my role as a health care professional. I would practice according to the sciences, and so I selected ocular pharmacology and advanced pharmacognosy for my electives. Poetry was for slackers.

This prejudice, strengthened by a graduate degree in research methodology and a growing emphasis on evidence-based medicine, would persist over the first couple of decades of my career. Then, over the subsequent two decades, I came to understand what R.S. Downie meant when he said, "that there can be tools other than scientific ones for dealing with the sickness, anxieties, and tears of human life." 1(pxi) I turned to the humanities, literature, art, and performance as a tool to learn about what people go through with their diseases, disorders, and injuries apart from their encounters with health care professionals and institutions that are singularly focused on medical science (what I will call "biomedicine"). What I discovered convinced me that the humanities should be an essential component in the education of pharmacists. My aim in this commentary is to make a case for incorporating the humanities into pharmacy education and to suggest some approaches for educators to consider.

The biomedical gaze was enough for me when I was posted in an intensive care unit right after completing a pharmacy residency. Dobutamine infusions got low

Corresponding Author: J. Russell Teagarden, Brookfield, CT. Tel: 203-947-1504. Email: russell.teagarden@gmail.com cardiac outputs up, and nitroprusside got high blood pressures down. $\mathrm{H}_{2}$-receptor antagonists prevented gastric ulcers from forming, and beta-blockers prevented hearts from racing. Atoms, molecules, and numbers explained all that was going on and all that was going to be done. Science had health care professionals covered.

Subsequent roles involving drug use and drug payment policies pried my gaze away from individual patients and towards patient populations. This wider gaze came with a creeping realization that what health problems pose for people involves more than the pathophysiological basis of disease. Bjørn Hofmann's model for health problems provided a foundation for these creeping realizations. ${ }^{2}$ The model divides health problems into three components: disease, illness, and sickness. Disease refers to the pathophysiological mechanisms causing health problems, illness refers to the experiences that health problems create for people, and sickness to the sociological responses to health problems.

Eric Cassell offers a more prosaic distinction between disease and illness when he says, "Let us use the word 'illness' to stand for what the patient feels when he goes to the doctor, and 'disease' for what he has on the way home from the doctor's office. Disease, then, is something an organ has; illness is something a man has. ${ }^{3(\mathrm{p} 48)}$ The illness experience is determined to some degree on how people understand their health problems, and what their health problems force them to confront and manage, such as work and family matters, and the obstacles to getting health care. Kleinman has likened the illness experience, especially the chronic illness experience, to a "volcano: it does not go away. It menaces. It erupts. It is out of control. One damned thing follows another."4(p44) 


\section{American Journal of Pharmaceutical Education 2020; 84 (4) Article 7636.}

When disease and illness are distinguished in this way, the primary focus of biomedicine on disease becomes evident with its foundation in the sciences. Illness experiences get less attention, which creates a gap in the preparation of clinicians that the humanities can address. After all, the human condition has been the central interest of the humanities as long as humans have reflected on their state, and "suffering and illness," as Tymieniecka frame them, "are part and parcel of life, an inherent condition of its unfurling." (pxviii) "Birth, death, and frailty in between. Rise and fall- this was the doctor's business, and it was literature's too," says a character in Ian McEwan's novel Atonement. ${ }^{6(\mathrm{p} 87)}$ I would add that it is not just the doctor's business, but also the business of all health care professionals, and the business of the arts as well.

What can illness experiences look or feel like according to the arts? The neurological phenomenon of aura before a seizure in Paul Hardy's novel Tinkers is described as, "not the lightening, but the cooked air the lightening pushed in front of itself," "(p47) and shown in Bryn Higgins' movie, Electricity, as "here's the shimmer. . and I'm falling down the rabbit hole."8 The polydypsia and polyuria of diabetes in James Dickey's poem "Diabetes" is, "One night I thirsted like a prince/Then like a king/Then like an empire like a world/On fire. I rose and flowed away..."9(p199) The confusion, memory loss, and disorientation someone with dementia could experience is created through the set designs, lighting effects, scene sequences, and time loops in Florian Zeller's play, The Father. ${ }^{10}$ Tuberculosis as a consequence of living conditions is portrayed in Alice Neel's painting, T. B. Harlem. ${ }^{11}$

A role for the humanities in pharmacy education is becoming increasingly important if pharmacists are to advance their working relationships with physicians in patient care. Humanities courses are required in $80 \%$ of North American allopathic and osteopathic medical schools, and elective humanities courses are offered in $70 \%$; an average of over 40 hours of instruction in the humanities is provided. ${ }^{12}$ Many medical schools now support these courses through formal medical humanities sections or programs. The content and structure of the humanities programming in medical schools vary in depth and breadth, but nevertheless convey an expectation that physicians will apply knowledge and insights they gained from the humanities to the care of their patients. Pharmacists will be better able to collaborate with them in patient care when they access the same knowledge and insights.

Getting the humanities into pharmacy education can be done the old-fashioned way, ie, through individual courses (preferably required courses). These courses could bring attention to works that extend or elaborate on biomedical concepts students learned in other courses and that render illness experiences such that students can see their breadth and feel their effects. Another approach could involve applying particular works from the arts to specific clinical situations covered within therapeutics courses and practice experiences, which would add relevance and immediacy for students. Links to relevant works could be embedded into materials used for therapeutics courses as they correspond to a covered topic, ie, "just in time" humanities. As part of a course or as an extracurricular activity, students could be given the opportunity to create their own renderings of illness experiences through any genre of the arts. ${ }^{13,14}$

Finding and selecting the works and integrating them into course work and practice experiences will challenge many pharmacy schools. They are pressed for time and space in their curriculums, and few if any of their faculty members are humanities scholars. Forming partnerships with faculties in the humanities, especially those in affiliated medical schools, could be an efficient way to get robust and relevant curriculum and experiential elements. Or humanities scholars could be brought onto pharmacy school faculties, such as the humanities professor I resented as a student but now wish I was. Over the past few decades, medical humanities has become a recognized field with its own cannon, scholarship, and curricula, which faculties can access for use in pharmacy education. When the right content and programming are selected, the students will experience new discoveries and exhilaration, as I did and still do.

Any credible patient-centric care model will recognize the obligations health care professionals carry to account for both disease and illness. The humanities offer them opportunities to broaden their understandings of illness experiences (all those damned things that follow one another) and to expand their responses to them. Pharmacists will be better prepared for patient-centric care when literature, art, and performance are added to their education and training: an idea I once thought was offensive but now know to be essential, and an idea Goethe foresaw as inevitable about 200 years ago when he said, "Science arose from poetry... when times change the two can meet again on a higher level as friends." 15 Times have changed, poetry is for pharmacists.

\section{ACKNOWLEDGMENTS}

Lee Simon, MHPE, David Angaran, MS, Lucy Bruell, MS, and Alexis Teagarden, $\mathrm{PhD}$, provided insightful thoughts on my argument. Lucy Bruell also provided editorial input. 


\section{American Journal of Pharmaceutical Education 2020; 84 (4) Article 7636.}

\section{REFERENCES}

1. Downie RS, ed. The Healing Arts: An Oxford Illustrated Anthology. New York, NY: Oxford University Press; 1994.

2. Hofmann B. On the Triad of Disease, Illness and Sickness. J Med Philos. 2002;27(6):651-673.

3. Cassell E. The Healer's Art. Cambridge, Massachusetts: MIT Press; 1985.

4. Kleinman A. The Illness Narratives: Suffering, Healing \& the Human Condition. New York, NY: Basic Books; 1988.

5. Tymieniecka A-T. Illness, Life, and the Human Condition. In: Tymieniecka A-T, Agazzi E, eds. Life - Interpretation and the Sense of Illness within the Human Condition: Medicine and Philosophy in a Dialogue. Milan, Italy: Kluwers Academic; 1998:xv-xxi.

6. McEwan E. Atonement. New York, NY: Anchor Books; 2001.

7. Harding P. Tinkers. New York, NY: Bellevue Literary Press; 2009.

8. Higgins B. Electricity. [DVD]. London, UK: Stone City Films; 2015.
9. Dickey J. Diabetes. In: Reynolds R, Stone J. eds. On Doctoring. New York, NY: Simon \& Schuster; 2001.

10. Zeller F. The Father. [Play]. Samuel J. Friedman Theater. New York, NY: Manhattan Theater Club; 2016.

11. Neel A. T. B. Harlem. [Painting.] USA: National Museum of Women in the Arts; 1940.

12. Klugman CM. Medical humanities in allopathic and osteopathic medical schools. J Med Humanit. 2018;39:473-481.

13. Teagarden JR. Well connected: pharmacy education and the humanities. J Med Humanit. 2013;34(4):477-480.

14. Teagarden JR, Assa-Eley M, Nemire RE. Illness performed and imagined: an elective course using the humanities to teach student pharmacists about illness. Curr Pharm Teach Learn.

2013;5(2):120-128.

15. Miller D, ed. Goethe: The Collected Works. Vol. 12. Princeton, NJ: Princeton University Press; 1995. 